\title{
The Effects of Socio-demographic Characteristics on Indonesian Women's Knowledge of HIV/AIDS: A Cross-sectional Study
}

\author{
Putu Erma Pradnyani, Arief Wibowo, Mahmudah \\ Department of Biostatistics of Public Health, Airlangga University, Surabaya, Indonesia
}

Objectives: The purpose of this study was to characterize Indonesian women's knowledge of HIV/AIDS and to investigate the effects of socio-demographic characteristics thereupon with the goal of supporting the prevention and early detection of HIV/AIDS.

Methods: This cross-sectional study was conducted using secondary data from the standard Indonesian Demographic and Health Survey (IDHS) in 2012. A total of 34984 subjects ranged in age from 15 years to 49 years. Data were analyzed using the chi-square test and logistic regression to identify the effects of socio-demographic characteristics on Indonesian women's knowledge of HIV/AIDS.

Results: All socio-demographic characteristics except marital status were related to knowledge of HIV/AIDS among Indonesian women in the univariate analysis $(p<0.05)$. Multivariate analysis revealed that only age group, education level, location of residence, and wealth index were related to Indonesian women's knowledge of HIV/AIDS $(p<0.05)$.

Conclusions: Indonesian women's insufficient knowledge related to HIV/AIDS shows that the provision of accurate and comprehensive information related to HIV/AIDS are components of prevention and control interventions that should be improved. With greater knowledge, women are expected to be more likely to determine their own and their partners' human immunodeficiency virus status and to take appropriate preventive steps.

Key words: HIV/AIDS, Knowledge, Social demographic, Infectious disease, Indonesia

\section{INTRODUCTION}

Globally the number of people living with HIV/AIDS (PLWHA) increased from 27.4 million to 33.7 million people from 2000 to 2012. A total of 2.1 million new cases were reported through 2012 [1]. January until March 2017, 10376 people were re-

Received: November 4, 2018 Accepted: January 16, 2019

Corresponding author: Putu Erma Pradnyani, BPH

Department of Biostatistics of Public Health, Airlangga University,

Surabaya 60112, Indonesia

E-mail: putu.erma.pradnyani@fkm.unair.ac.id

This is an Open Access article distributed under the terms of the Creative Commons Attribution Non-Commercial License (http://creativecommons.org/licenses/bync/4.0// which permits unrestricted non-commercial use, distribution, and reproduction in any medium, provided the original work is properly cited. ported to have been infected with human immunodeficiency virus (HIV) in Indonesia that year [2]. It is estimated that many PLWHA are not aware that they are infected, mainly because of the limited availability and uptake of voluntary counseling and testing (VCT) for HIV. The continued existence of a mindset that stigmatizes people who use VCT services as being at risk of contracting HIV severely hampers efforts to respond to the acquired immune deficiency syndrome (AIDS) epidemic [3]. Many people do not want to receive VCT services due to this stigma and the resulting discrimination [4].

As of 2017, HIV prevalence in women was 33.8\% less than in men, but women are at high risk of contracting the virus from their husbands or partners and can even transmit HIV to a fetus during pregnancy or during childbirth [5]. Therefore, wom- 
en and children comprise an emerging risk group for HIV. The results of a previous study indicated that women's knowledge of HIV/AIDS is lower than that of men; therefore, if women do not have accurate knowledge about HIV/AIDS, especially information related to how to determine their own and their partners' HIV status and how to respond to that information, many new cases of HIV will continue to occur $[6,7]$.

Knowledge about HIV/AIDS can take the form of knowledge about the modes of HIV transmission, how to prevent HIV (condom use), early detection (e.g., VCT services), and perceptions of PLWHA [8]. The level of knowledge about HIV in women in Indonesia remains very low, as previous studies have shown that many young women still do not know how HIV is transmitted and are unaware of methods of prevention and early detection [9]. Knowledge of VCT services can help individuals to become aware of their HIV status through HIV testing with pre-test and post-test counseling. VCT is a client-driven initiative, not a form of testing and counseling initiated by service providers in the context of clients seeking health care for other reasons [10].

A study from sub-Saharan Africa reported that socio-demographic characteristics such as socioeconomic inequality have a powerful impact on HIV transmission, despite not directly reflecting the adequacy of individuals' knowledge [11]. Other studies have also reported that occupational and marital status were associated with behaviors related to HIV [12]. Knowledge related to HIV/AIDS was found to be positively correlated with behaviors related to HIV/AIDS prevention [8]. The purpose of this study was to determine the level of knowledge of HIV/AIDS among women in Indonesia and to investigate how socio-demographic factors affected Indonesian women's knowledge regarding HIV/AIDS.

\section{METHODS}

\section{Data}

This study used secondary data from the standard Indonesian Demographic and Health Survey (IDHS) in 2012. The IDHS aims to obtain detailed information about the Indonesian population, with an emphasis on family planning and health. The population of the IDHS in 2012 study was divided into men aged 15-54 years, young men aged 15-24 years, and women aged 15-49 years. The samples used were women of reproductive age (15-49 years). The sampling technique used for IDHS is multi-stage random sampling, grouped by province, district, and village grouped into urban-rural areas [13]. For this study, a sample of data from women participants was selected from the IDHS in 2012, and individuals with missing data were not analyzed. The total sample of this study was 34984 Indonesian women.

\section{Variables}

The dependent variable was women's knowledge about HIV measured by 12 statements related to VCT knowledge, modes of transmission, HIV prevention, and perceptions related to PLWHA. Knowledge about VCT was measured by whether the participant was aware of the VCT process and the location of VCT services. Knowledge of modes of transmission was measured by determining whether a participant that HIV could be transmitted through breastfeeding and sharing non-sterile needles, but not through sharing food, mosquito bites, and the supernatural or witchcraft. Knowledge of HIV prevention was measured by whether always using a condom during sex and having only one partner could prevent HIV. Perceptions related to PLWHA were determined from responses to items about whether PLWHA can continue to work, whether PLWHA can look healthy, and willingness to care for PLWHA. Knowledge about HIV was categorized as good or insufficient. A participant was considered to have good knowledge if she answered all 12 of these statements correctly; if there was a single incorrect answer, then the participant was classified as having insufficient knowledge. This is in accordance with the cut-off of the measurement of comprehensive knowledge about HIV [14].

The independent variables in this study were the socio-demographic characteristics of the women aged 15-49 years who comprised the IDHS sample. The participants were categorized into 7 age groups, and level of education was dichotomized as high (if a respondent had completed high school or college) or low (for education levels ranging from no school to junior high school). Locations of residence were divided into cities and villages according to the IDHS results. Marital status was categorized as unmarried, married, and divorced (or widowed). Occupational status was dichotomized as working and unemployed. The wealth index was assessed by indicators of household wealth based on the location of residence, and participants were grouped into 5 categories according to the wealth index. 
Table 1. HIV knowledge indicators

\begin{tabular}{lc}
\hline Indicators & Correct answers \\
\hline VCT knowledge & \\
Knowledge of VCT location & $2587(7.4)$ \\
Knowledge of VCT process & $3652(10.4)$ \\
Modes of transmission & \\
HIV is transmitted by breastfeeding & $28510(81.5)$ \\
People get HIV by sharing unsterilized needles & 32127 (92.0) \\
Cannot get HIV by sharing food & 15027 (43.0) \\
Cannot get HIV from mosquito bites & 16022 (45.8) \\
Cannot get HIV from witchcraft & 27622 (79.2) \\
Prevention & \\
Always use condom during sex & 19552 (56.0) \\
Have only 1 partner & 26260 (75.2) \\
Perceptions related to PLWHA & \\
A woman with HIV can continue to work & 16938 (48.7) \\
Willing to care for PLWHA & 24425 (69.8) \\
A healthy-looking person can have HIV & 28013 (80.2)
\end{tabular}

Values are presented as number (\%).

HIV, human immunodeficiency virus; VCT, voluntary counseling and testing; PLWHA, people living with HIV/AIDS.

\section{Statistical Analysis}

The chi-square test was used in the univariate and multivariate analyses to characterize the overall effects of socio-demographic variables on knowledge using logistic regression analysis with Stata version 12 (StataCorp., College Station, TX, USA) at a significance level (a) of 0.05 . The results are presented as odds ratios (ORs) with $95 \%$ confidence intervals (Cls) and $p$ values to indicate the magnitude and statistical significance of associations.

\section{RESULTS}

Of the 12 items used to measure knowledge of HIV (Table 1), the lowest proportion of correct answers was found for the item on the location of VCT services (7.4\%), and the highest proportion of correct answers was found for the item inquiring about whether respondents knew that HIV can be transmitted through sharing non-sterile needles (92.0\%).

Table 2 shows the distribution of the socio-demographic characteristics (age group, occupational status, marital status, education, location of residence, and wealth index) of Indonesian women according to knowledge of HIV. The age group of 30-34 years had the highest proportion of good knowledge of HIV (1.5\%), while only $0.3 \%$ of respondents in the age group of 15-19 years had good knowledge of HIV.
Table 2. Distribution of women's knowledge of HIV/AIDS by socio-demographic characteristics

\begin{tabular}{|c|c|c|c|}
\hline \multirow[t]{2}{*}{ Characteristics } & \multicolumn{2}{|c|}{ HIV knowledge } & \multirow{2}{*}{$\begin{array}{c}\begin{array}{c}\text { Univariate } \\
\text { analysis }\end{array} \\
p \text {-value }\end{array}$} \\
\hline & Insufficient & Good & \\
\hline Age (y) & & & $<0.001$ \\
\hline $15-19$ & 5855 (99.7) & $19(0.3)$ & \\
\hline $20-24$ & $5225(98.7)$ & $68(1.3)$ & \\
\hline $25-29$ & 5678 (99.3) & $42(0.7)$ & \\
\hline $30-34$ & 5489 (98.5) & $85(1.5)$ & \\
\hline $35-39$ & 5154 (99.1) & $47(0.9)$ & \\
\hline $40-44$ & 4234 (98.9) & $45(1.1)$ & \\
\hline $45-49$ & 3016 (99.1) & $27(0.9)$ & \\
\hline Occupational status & & & $<0.001$ \\
\hline Unemployed & $16144(99.4)$ & $93(0.6)$ & \\
\hline Working & 18504 (98.7) & $243(1.3)$ & \\
\hline Marital status & & & 0.592 \\
\hline Never married & $8657(98.9)$ & $92(1.0)$ & \\
\hline Married & 24516 (99.1) & $228(0.9)$ & \\
\hline Divorced/widowed & 1479 (99.3) & $12(0.7)$ & \\
\hline Education level & & & $<0.001$ \\
\hline Low & 29370 (99.6) & $105(0.3)$ & \\
\hline High & $5283(95.9)$ & $226(4.1)$ & \\
\hline Place of residence & & & $<0.001$ \\
\hline Rural & 14219 (99.5) & $67(0.5)$ & \\
\hline Urban & 20434 (98.7) & $264(1.3)$ & \\
\hline Wealth index & & & $<0.001$ \\
\hline Poorest & 3790 (99.7) & $10(0.3)$ & \\
\hline Poorer & 5969 (99.8) & $14(0.2)$ & \\
\hline Middle & 7349 (99.5) & $34(0.4)$ & \\
\hline Richer & 8341 (99.1) & $76(0.9)$ & \\
\hline Richest & 9202 (97.9) & $199(2.1)$ & \\
\hline
\end{tabular}

Values are presented as number (\%). HIV, human immunodeficiency virus.

Among women who were unemployed, $0.6 \%$ had good knowledge of HIV. Unmarried women had the highest percentage of good HIV knowledge compared to other groups defined by marital status. Women who had a high level of education (high school to college) were relatively likely (4.1\%) to have good knowledge of HIV. Women living in urban areas had a higher level of good knowledge of HIV (1.3\%) than their rural counterparts. Based on the level of wealth, the most affluent women had better knowledge of HIV than those in other categories. The chi-square test showed that all socio-demographic characteristics, except marital status, were related to HIV knowledge among Indonesian women $(p<0.05)$.

The results of multivariate analysis with multiple logistic re- 
Table 3. Multiple logistic regression analysis of the effects of socio-demographic characteristics on women's knowledge of HIV/AIDS

\begin{tabular}{|c|c|c|}
\hline \multirow{2}{*}{ Characteristics } & \multirow{2}{*}{$\begin{array}{c}\text { Model } 1 \\
\text { cOR }(95 \% \text { Cl) }\end{array}$} & \multirow{2}{*}{$\begin{array}{c}\text { Model } 2 \\
\text { aOR }(95 \% \text { CI) }\end{array}$} \\
\hline & & \\
\hline \multicolumn{3}{|l|}{ Age (y) } \\
\hline $15-19$ & 1.00 (reference) & 1.00 (reference) \\
\hline $20-24$ & $4.03(1.93,8.38)^{* * *}$ & $1.17(0.97,1.41)$ \\
\hline $25-29$ & $2.15(1.01,4.58)^{*}$ & $1.35(1.10,1.64)^{* *}$ \\
\hline $30-34$ & $4.77(2.33,9.78)^{* * *}$ & $1.55(1.26,1.90)^{* * *}$ \\
\hline $35-39$ & $2.79(1.29,6.04)^{* *}$ & $1.36(1.10,1.68)^{* *}$ \\
\hline $40-44$ & $3.30(1.53,7.09)^{* *}$ & $1.15(0.92,1.44)$ \\
\hline $45-49$ & $2.71(1.18,6.21)^{*}$ & $0.94(0.73,1.22)$ \\
\hline \multicolumn{3}{|l|}{ Occupational status } \\
\hline Unemployed & 1.00 (reference) & 1.00 (reference) \\
\hline Working & $2.41(1.68,3.47)^{* * *}$ & $1.02(0.93,1.13)$ \\
\hline \multicolumn{3}{|l|}{ Marital status } \\
\hline Never married & 1.00 (reference) & 1.00 (reference) \\
\hline Married & $0.88(0.61,1.25)$ & $0.90(0.77,1.05)$ \\
\hline Divorced/widowed & $0.67(0.28,1.58)$ & $0.80(0.60,1.05)$ \\
\hline \multicolumn{3}{|l|}{ Education level } \\
\hline Low & 1.00 (reference) & 1.00 (reference) \\
\hline High & $11.99(8.49,16.93)^{* * *}$ & $2.43(2.17,2.72)^{* * *}$ \\
\hline \multicolumn{3}{|l|}{ Place of residence } \\
\hline Rural & 1.00 (reference) & 1.00 (reference) \\
\hline Urban & $2.75(1.85,4.10)^{* * *}$ & $1.33(1.19,1.49)^{* * *}$ \\
\hline \multicolumn{3}{|l|}{ Wealth index } \\
\hline Poorest & 1.00 (reference) & 1.00 (reference) \\
\hline Poorer & $0.94(0.39,2.29)$ & $1.04(0.85,1.26)$ \\
\hline Middle & $1.81(0.72,4.49)$ & $1.33(1.10,1.62)^{* *}$ \\
\hline Richer & $3.51(1.50,8.21)^{* *}$ & $1.63(1.36,1.98)^{* * *}$ \\
\hline Richest & $8.56(3.81,19.25)^{* * *}$ & $2.13(1.77,2.57)^{* * *}$ \\
\hline
\end{tabular}

cOR, crude odds ratio; aOR, adjusted odds ratio; $\mathrm{Cl}$, confidence interval. ${ }^{*} p<0.05,{ }^{* *} p<0.01,{ }^{* * *} p<0.001$.

gression (Table 3) show that 2 models were formed using the enter method, with model 1 being a crude model and model 2 being a multivariate model. In model 2 , the age categories of 25-39 years, education level, residence, and level of wealth (except the poor category) showed significant effects on Indonesian women's knowledge of HIV. The 30-34 years age group had an OR of 1.55 for having good knowledge of HIV compared to women aged 15-19 years. Women with a high education level demonstrated an OR for having good HIV knowledge of 2.43 compared to women who had a low education level. Women who lived in cities were 1.33 times more likely to have good knowledge of HIV/AIDS than women who lived in villages. The richest women were 2.13 times more likely to have good knowledge of HIV/AIDS than the poorest women.

\section{DISCUSSION}

The results of this study show that very few women in Indonesia had a comprehensive knowledge of HIV/AIDS. This result is similar to the findings of previous studies that revealed levels of knowledge of HIV/AIDS to still be low to moderate [15]. Comprehensive education on HIV/AIDS needs to be provided to women to prevent new HIV cases. Looking deeper into respondents' knowledge of HIV/AIDS, the fewest correct responses were found for knowledge of VCT services, although testing is the only way to know one's HIV status [16]. Knowledge of VCT has been disseminated through health services, print media, and social media, but the stigma of using VCT services means that information about VCT services may be ignored $[17,18]$. In contrast, a similar study found a high level of knowledge about VCT services among women, especially where to access VCT [19]. Dissemination of information about the benefits of VCT services in a way that reduces the existing stigma regarding these services would be an excellent step towards reducing new HIV cases, because VCT allows women to know their status.

Although the highest levels of knowledge were shown for how HIV is transmitted (through risky behavior, including unprotected sexual intercourse, the use of unsterile needles, blood, and breast milk), 100\% of Indonesian women should have this knowledge [9]. As such, our findings are similar to those of previous study that reported the continued presence of many women who did not have sufficient knowledge about HIV/AIDS transmission [4].

A person's knowledge can be affected by his or her surrounding environment, as partially reflected by socio-demographic characteristics. Table 3 shows that in model 1 all age groups 20+ years had significantly higher ORs for good knowledge about HIV / AIDS compared to the 15-19 year age group; However, in model 2 or multivariate model, this relationship was only found for the 25-39 year age group. This finding is similar to that of previous research stating that age plays an important role in knowledge of HIV/AIDS [20]. The 15-19 year age group had the lowest level of knowledge because they are still receiving education, and if they discontinue schooling, they will receive very limited access to information and knowledge. 
Characteristics such as occupational status and marital status showed a significant relationship with knowledge of HIV/ AIDS in the univariate analysis $(p<0.05)$, but these relationships were not found in the multivariate analysis. This result is unlike that of a previous study that found significant relationships between marital and occupational status and knowledge of HIV/AIDS among young women aged 15-24 years [21].

Education level affected women's knowledge of HIV/AIDS. A high level of education increased the chances of women having good knowledge of HIV/AIDS, which may have been because higher education causes women to be more proactive about their own health and to seek out information to protect themselves against HIV/AIDS. Previous research has also shown similar results, with higher levels of education linked to wider knowledge about HIV, especially modes of HIV transmission [22]. Therefore it is very important for women to receive higher levels of education (at least equal to that of men) so that their insights and knowledge will increase, especially with regard to maintaining HIV-free status.

Urban residence also increased women's likelihood of having good knowledge of HIV/AIDS. It is well established that life in larger cities provides greater access to sources of information about HIV/AIDS and reduces the stigma of HIV/AIDS. Previous research explained that location of residence is a form of imbalance, especially in accessing information or health services, that impacts the level of one's knowledge [23]. Previous research has stated that urban populations are particularly vulnerable to HIV infection, especially women and children, but this trend can be overcome by access and adequate health services [24]. It is not surprising that good levels of knowledge related to HIV/AIDS were less common in rural areas than in cities. Therefore, it is necessary to empower rural communities, especially in terms of increasing women's knowledge and capacity.

Wealth also affected women's knowledge of HIV/AIDS. Similar results were obtained in previous studies that reported a positive relationship between the wealth index and women's knowledge of HIV/AIDS. The richest women were 1.47 and 2.03 times more likely to have adequate knowledge of HIV/ AIDS than the poorest women in the Democratic Republic of the Congo (adjusted OR, 1.47; 95\% Cl, 1.18 to 1.82) and Nigeria (adjusted OR, 2.03; $95 \% \mathrm{Cl}, 1.71$ to 2.40 ) [21]. Other studies have also reported that wealth inequality was a significant predictor of HIV-related knowledge because wealth inequality could hinder access to accurate information about HIV [11].
A limitation of this study is that not all socio-demographic characteristics were analyzed, and there were some missing data that were not included in the analysis. Nonetheless, it is concluded that the low levels of knowledge related to HIV/ AIDS shown by women in Indonesia indicate that the provision of accurate and comprehensive information related to HIV/AIDS should be emphasized as a component of interventions to prevent HIV transmission by increasing access or enhancing community empowerment (especially focusing on women). With accurate and comprehensive knowledge, it is expected that women will be more likely to determine their or their partners' HIV status early, thereby preventing the emergence of new cases of HIV.

\section{CONFLICT OF INTEREST}

The authors have no conflicts of interest associated with the material presented in this paper.

\section{ACKNOWLEDGEMENTS}

This program was supported by the DHS program and implemented by ICF International.

\section{ORCID}

Putu Erma Pradnyani https://orcid.org/0000-0001-68272764

Arief Wibowo https://orcid.org/0000-0003-2283-1350

Mahmudah https://orcid.org/0000-0002-7434-0847

\section{REFERENCES}

1. UNAIDS. Global HIV \& AIDS statistics - 2018 fact sheet [cited 2018 Aug 25]. Available from: http://www.unaids.org/en/resources/fact-sheet.

2. Indonesian Ministry of Health. Report on the progress of HIVAIDS and the first quarter of the 2017 sexually transmitted infectious diseases (PIMS) [cited 2018 Aug 25]. Available from: http://siha.depkes.go.id/portal/files_upload/Laporan_HIV_ AIDS_TW_1_2017_rev.pdf (Indonesian).

3. Family Health International. Voluntary counseling and testing for HIV: a strategic framework; 2003 [cited 2019 Feb 28]. Available from: http://www.hivpolicy.org/Library/HPP000527.pdf.

4. Asadi-Aliabadi M, Abolghasemi J, Rimaz S, Majdzadeh R, Ros- 
tami-Maskopaee F, Merghati-Khoei E. Barriers to health service utilization among iranian female sex workers: a qualitative study. J Prev Med Public Health 2018;51(2):64-70.

5. Mavhu W, Rowley E, Thior I, Kruse-Levy N, Mugurungi O, Ncube $\mathrm{G}$, et al. Sexual behavior experiences and characteristics of male-female partnerships among HIV positive adolescent girls and young women: qualitative findings from Zimbabwe. PLoS One 2018;13(3):e0194732.

6. Umam MK, Hemchayat M, Wetasin K. The gender differences in sexual behavior, HIV/AIDS knowledge and perceptions about HIV/AIDS among university students in Indonesia; 2016 [cited 2019 Feb 28]. Available from: http://www.worldresearchlibrary. org/up_proc/pdf/184-145517088723-27.pdf.

7. Walcott MM, Hatcher AM, Kwena Z, Turan JM. Facilitating HIV status disclosure for pregnant women and partners in rural Kenya: a qualitative study. BMC Public Health 2013;13:1115.

8. Mulu W, Abera B, Yimer M. Knowledge, attitude and practices on HIV/AIDS among students of Bahir Dar University. Sci J Public Health 2014;2(2):78-86.

9. Ngoma CM, Roos J, Siziya S. Knowledge about HIV and AIDS among young women. Open J Nurs 2015;5:558-565.

10. USAID. Voluntary counseling and testing rigorous evidence usable results; 2012 [cited 2018 Aug 25]. Available from: https://www.jhsph.edu/research/centers-and-institutes/research-to-prevention/publications/VCT.pdf.

11. Faust $L$, Yaya $S$, Ekholuenetale $M$. Wealth inequality as a predictor of HIV-related knowledge in Nigeria. BMJ Glob Health 2017;2(4):e000461.

12. Korra A, Bejiga M, Tesfaye S. Socio-demographic profile and prevalence of HIV infection among VCT clients in Addis Ababa. Ethiop J Health Dev 2005;19(2):109-115.

13. Statistics Indonesia. Demographic and Health Survey 2012; 2013 [cited 2019 Feb 28]. Available from: https://dhsprogram. com/pubs/pdf/fr275/fr275.pdf.

14. Angkasawati TJ, Arifin A. Comprehensive knowledge and attitudes to HIV / AIDS in the friendly age woman group (WUS) in
Indonesia on 2007. Health Syst Res Bull 2010;13(2):140-150 (Indonesian).

15. Fraim NL. Knowledge levels and misconceptions about HIV/ AIDS: what do university students in Turkey really know. Int J Humanit Soc Sci 2012;2(2):50-58

16. Ali AA, Osman E. Factors influencing HIV voluntary counseling and testing (Vct) among pregnant women in Kassala, Eastern Sudan. J Womens Health Care 2014;3(6):198.

17. Ndwiga T, Omwono M. A study of factors influencing VCT service utilization among the youths: a case study of Kapsabet Division, Nandi County, Kenya. World J AIDS 2014;4:281-286.

18. Churcher S. Stigma related to HIV and AIDS as a barrier to accessing health care in Thailand: a review of recent literature. WHO South East Asia J Public Health 2013;2(1):12-22.

19. Kirakoya-Samadoulougou F, Jean K, Maheu-Giroux M. Uptake of HIV testing in Burkina Faso: an assessment of individual and community-level determinants. BMC Public Health 2017; 17(1):486.

20. Okeke CE, Onwasigwe CN, Ibegbu MD. The effect of age on knowledge of HIV/AIDS and risk related behaviours among army personnel. Afr Health Sci 2012;12(3):291-296.

21. Gebremedhin SA, Wang Y, Tesfamariam EH. Predictors of HIV/ AIDS knowledge and attitude among young women of Nigeria and Democratic Republic of Congo: cross-sectional study. J AIDS Clin Res 2017;8(3):677.

22. Mwamwenda TS. Education level and HIV/AIDS knowledge in Kenya. J AIDS HIV Res 2014;6(2):28-32.

23. Schafer KR, Albrecht $H$, Dillingham R, Hogg RS, Jaworsky D, Kasper K, et al. The continuum of HIV care in rural communities in the United States and Canada: what is known and future research directions. J Acquir Immune Defic Syndr 2017; 75(1):35-44

24. Van Donk M. "Positive" urban futures in sub-Saharan Africa: HIV/AIDS and the need for ABC (A Broader Conceptualization). Environ Urban 2006;18(1):155-175. 